\title{
Competition in Price and Availability when Availability is Unobservable
}

\author{
James D. Dana, Jr. ${ }^{\dagger}$ \\ Northwestern University
}

June 2000

Keywords: Service Rate, Service Level, Inventory, Newsboy Model, Demand Uncertainty, Pricing, Price Rigidities

\begin{abstract}
This paper presents a strategic model of competition in both price and availability when firms can publicly commit to prices but not inventories (or capacities). Demand is uncertain and firms may stock out in equilibrium. Consumers choose where to shop given the price and expected availability at each firm (the probability of being served). In a one period model, I show that firms can use higher prices to "signal" higher availability (regardless of whether price or inventory is chosen first). This generates a floor on equilibrium prices and industry profits that exists regardless of the number of firms in the industry. In a repeated game, firms that maintain reputations for higher service rates may earn even higher profits. The model sheds light on the relationship between price, availability, and reputations in the video rental industry.
\end{abstract}

\footnotetext{
$\dagger$ Associate Professor, Department of Management and Strategy, J. L. Kellogg Graduate School of Management, Northwestern University, 2001 Sheridan Road, Evanston, IL 60208-2013. Phone: 8474913465 . Fax: 847467 1777. E-mail: j-dana@nwu.edu. Current drafts of the author's working papers are available on the Internet at http://www.kellogg.nwu.edu/faculty/dana. I would like to thank Sandeep Baliga, Bart Lippman, Claudio Mezzetti, Roger Myerson, Kathryn Spier, Juuso Valimaki, and especially Andrew Daughety, Jennifer Reinganum, and Jeroen Swinkles for helpful comments, however any remaining errors are my own. This research was supported by the National Science Foundation (grant number SES-9905143).
} 


\section{Introduction}

Competition in availability or service rates (the likelihood a consumer is served) is common in many retail and consumer service markets. Among the many retailers who regularly advertise availability are car dealers, video rental chains, department stores, mail order suppliers, and appliance stores. In many other industries, including movie theaters, book stores, and department stores, firms' reputations for availability clearly influence demand. ${ }^{1}$ But while consumers directly value high service rates because of the delays and search costs associated with stockouts, they often rely on past experience, reputations, advertising, and other signals to predict availability because inventories are unobservable. ${ }^{2}$

When aggregate demand is uncertain, inventory or capacity is fixed, prices are rigid, and search (for availability) is costly, then consumers, who want to avoid potential stockouts, choose where to shop on the basis of both price and the expected likelihood of a being served. ${ }^{3}$ Carlton (1979) derived the zero-profit competitive equilibrium of such a model under the assumption that firms simultaneously and observably commit to price and inventory ${ }^{4}$. Peters (1984) and Deneckere and Peck (1995) showed that a pure strategy equilibrium exists in the analogous oligopoly model if the number of firms is sufficiently large. 5

This paper departs from this previous work on service rate competition by making the more realistic assumption that consumers do not observe firms' inventories. ${ }^{6}$ Asymmetric information about inventories changes the way firms compete in prices in an important and interesting way. Consumers realize that firms with high margins are more

\footnotetext{
${ }^{1}$ Even airlines and hotels cater to some market segments that value firms' reputations for availability.

2I use inventory and capacity interchangeably to describe a firm's output decision when it must choose its output before its demand is known.

3 Price rigidities alone introduce the possibility of industry wide stockouts (see Prescott, 1976, Eden, 1990, Deneckere, Marvel, and Peck, 1996, and Dana, 1994), but costly search causes consumers to care about individual firms' stockout rates.

${ }^{4}$ See also Bryant (1980) and Gould (1978).

5Peters (1984) and Carlton (1978) consider models in which the aggregate demand is certain but individual firm's demand is uncertain (in Peters this is formally because there are a finite number of "large" buyers) but this distinction does not change the interpretation of the results.

${ }^{6}$ This assumption also captures the unobservability of the firm's expected demand.
} 
likely to stock inventory and are less likely to have stockouts. So a potential price increase has two offsetting effects: first, it decreases a consumer's surplus conditional on trade taking place, and second, it induces the firm to hold greater inventory, which increases the likelihood that trade takes place and a consumer's ex ante expected surplus from visiting the store.

The video rental industry is on where we might expect to see these patterns. I collected a small sample of prices and availability of video rentals at stores within a 4-mile radius of Northwestern University. There were 20 stores, including seven Blockbuster Video stores, one Hollywood Video outlet, and four others that were part of chains. The other eight were independent outlets. I checked the availability of four new releases, two each on two different Saturday evenings. Overall the movies were available $64 \%$ of the time. At outlets with prices of $\$ 3.50$ or more they were available $78 \%$ of the time. At Blockbuster (average price of $\$ 3.81$ ) the movies were available $86 \%$ of the time. ${ }^{7}$ At the other chains (average price of $\$ 3.32$ ) the movies were available $60 \%$ of the time. At the other independents (average price \$2.62) they were available $48 \%$ of the time.

Although this was hardly a scientific study (neither the Northwestern University vicinity nor the movies were selected at random), the results suggest a strong relationship between price and availability. As important, they also suggest that Blockbuster's advertised claims of greater availability are well deserved and allow Blockbuster to charge higher prices.

I explore two closely related single period oligopoly models. In the first, firms commit to observable prices before they choose their inventory levels (I call this the Bertrand model). Consumers understand that firms setting higher prices have private incentives to offer greater availability. ${ }^{8}$ In the second, firms commit to their inventory levels

\footnotetext{
${ }^{7}$ Two of the movies were guaranteed to be available at Blockbuster. They were available $93 \%$ of the time. The other two were available $79 \%$ of the time.

8 The video rental industry seems to fit this Bertrand model's stylized assumptions reasonably well. Stores adjust prices infrequently but make inventory decisions for new releases every week. After sampling their first video rental outlet, many consumers do not visit a second store if their preferred movie is out-of-stock
} 
before they choose their prices (I call this the Cournot model). A firm's price acts as a "signal" of the inventory level it chose. In equilibrium consumers expect firms that offer higher prices to also offer greater availability. Although price does not signal inventory holdings in the commonly meant sense of hidden information with a separating equilibrium (there is no hidden information in the model), I show that a firm's off-the-equilibrium-path price effects consumers conjectures about its inventory choice. I find that the Cournot equilibrium price is higher than the Bertrand price and that the difference depends on the number of firms. As market becomes less concentrated the equilibrium price in the Cournot model converges to the Bertrand price. In both cases, equilibrium prices are supra competitive and firms earn strictly positive profits even when there are arbitrarily many firms.

The model is related to other papers in which high prices guarantee high quality, such as Allen (1984), Klein and Leffler (1981), Shapiro (1983), and Rogerson (1983 and 1987). ${ }^{9}$ However each of those models is dynamic and models some form of firm reputation that enables high quality to be rewarded with repeat business; they are actually more closely related to the dynamic extension of my model presented later in this paper. ${ }^{10}$ The paper in the "quality guaranteeing prices" literature that is most similar to the static model here is Wolinsky (1983). He considers a static model in which competitive firms

Of course, they may rent another title, so a multiproduct version of the model would be more appropriate. Also it is reasonable to expect consumers to have different tastes for availability, which would also explain the equilibrium correlation between price and availability.

${ }^{9}$ The paper is also related to the literature on efficiency wages. One could interpret the profits that competitive firms earn as a type of efficiency profit. In a simple principal-agent, hidden-action model when effort is unobservable the principal would like to induce the agent to exert high effort by offering payments to the agent that are contingent on an imperfect signal of effort. But if the agent has limited liability, it may be impossible to design an incentive compatible contract without relaxing the agent's individual rationality constraint. In this paper the absence of forward contracts plays the role of a limited liability constraint; the consumer (the principal) cannot punish the agent (the firm) when there are stockouts. In this paper the consumer, who prefers that the firm hold higher inventories, relaxes the firm's zero profit constraint in order to satisfy the firm's incentive compatibility constraint. However this analogy has several limitations. First, firms, not consumers, are setting prices. Second, prices are determined through strategic interaction among firms. And third, price may be chosen after inventory or capacity, in which case price is not acting as an incentive but as a signal of the firm's inventory level.

${ }^{10}$ Milgrom and Roberts (1986) show that high prices can signal high quality when the distribution of quality is exogenous, but they also rely on dynamic models with some form of repeat purchase. 
choose unobservable quality and observable prices and consumers engage in costly search for quality. ${ }^{11}$

I also briefly consider infinitely repeated versions of the two static games. When the games are repeated firms can have reputations for high service rates. The dynamic model is similar to that of Klein and Leffler (1981) in that there is no hidden information and equilibria exist both with and without reputations. I show that such reputations may lead firms to charge even higher prices and earn even profits. Hence reputations for availability may exist in equilibrium, but may benefit the firm through higher profits rather than benefit the consumer. Carlton (1978) conjectured that a model in which firms held reputations for service rates would justify his assumption that inventory is observable. I show that this conjecture is correct if the speed with which consumers learn about firms' service rates is sufficiently fast and many firms have reputations. However in this case firms are collectively worse off and a tacit agreement not to establish reputations for high service would raise industry profits.

Daughety and Reinganum (1991) consider the determination of availability in models where firms cannot commit to price, so consumers have imperfect information about both price and output. They compare monopoly and duopoly pricing under these assumptions and show that the relative provision of availability depends on the magnitude of consumers' exogenous search costs. ${ }^{13}$ For low search costs, when duopolists compete price lower than the monopoly price, firms provide less availability, but for high search costs, when the duopoly price is the same as the monopoly price, duopolists provide more availability.

\footnotetext{
${ }^{11}$ Consumers choose where to shop based on price, but after visiting a firm and verifying the firm's quality they decide whether to consume or to engage in more costly search. Wolinsky describes high prices as a signal of high quality in the same sense as I do in this paper; consumers expect that firms who offer higher prices chose higher quality. However like the other papers in this literature, Wolinsky considers competitive firms and ignores many strategic issues including the timing of firms' price and quality decisions.

${ }^{12}$ See Kohlberg and Mertens (1986) and van Damme (1989).

${ }^{13}$ See also Daughety and Reinganum (1992).
} 
The operations literature has considered the related problem of optimal inventory choice by a single firm when stockouts adversely effect future demand, but typically in models with an exogenous price and exogenously specified consumer behavior. These papers include Schwartz (1966 and 1970), Balcer (1980, 1983), Fergani (1976), and Robinson (1990). Conslik and Smallwood (1979) consider competition in the probability of a breakdown when firm quality choice is unobservable, a problem which is extremely similar to competition in service rates, however they also treat price and consumer behavior as exogenous. Gans (1999a and 1999b) has recently considered a much richer dynamic model of inventory decisions and consumer choice in which consumers learn about service rates over time, but he too considers an exogenous price.

This work is also related to work on competition in inventories. Lippman and McCardle (1997) consider a model in which uncertain demand is divided in various ways among competing firms with an exogenous price. ${ }^{14}$ However they assume that inventories do not effect consumer choice and that price is exogenous. However inventories affect rivals because consumers can costlessly (perhaps an epsilon cost) buy from other firms if the first firm they visit stocks out (though the firm pays an exogenous shortage cost).

In the next section I present the basic model. In the third section I solve the model under the assumption that firms commit to prices before inventory. In section 4 I solve the model under the assumption that firms commit to inventory or capacity before price. In section 5 I compare the equilibria to those that arise without imperfect information. In section 6 I consider a repeated version of the game in which firms can hold reputations. Section 7 considers some extensions of the model and offers concluding remarks.

\footnotetext{
${ }^{14}$ See also Parlar (1988) and Karjalainen (1992), and the survey by Porteus (1990).
} 


\section{The Model}

\section{Consumers}

I assume there are a continuum of ex ante symmetric consumers with potential unit reservation values, $v$. Aggregate demand is uncertain. Firms' products are homogeneous and there is a continuum of consumers, so there is no idiosyncratic demand uncertainty. Individual consumers learn whether or not they want the good in which case their utility is $v-p$ if they obtain it and zero otherwise. Consumers who want the good choose where to shop based on firms' announced prices and their expectations of the firms' capacities which, together with consumers' aggregate behavior, determine the probability that the consumer will be served at each firm. This probability is the firm's service rate (also known as the type 2 service levels or fill rates). The expected utility from visiting firm $i$ is $U_{i}=\left(v-p_{i}\right) s_{i}$, where $s_{i}$ is the expected service rate of firm $i$ (conditional on the consumer wanting the good) and $p_{i}$ is its price. Consumers visit at most one firm. I assume the cost of visiting a second firm is arbitrarily high. ${ }^{15}$ When the expected utility associated with each firm is the same, consumers mix over firms. I let $\left\{\phi_{1}, \ldots, \phi_{n}\right\}$ denote the vector of probabilities with which a consumer visits each firm and require that $\sum_{i=1}^{n} \phi_{i}=1$.

A firm's demand is equal to the aggregate demand times the share of consumers who choose to visit the firm. The total number of consumers who want the good is $a$. I assume that $a$ has a probability density function $f(a)$ which is strictly positive and continuous on $[\underline{a}, \bar{a}], 0 \leq \underline{a}<\bar{a}<\infty$, and a cumulative probability distribution $F(a)$. Expected demand for $p \leq v$ is $\mu=\int_{\underline{a}}^{\bar{a}} a f(a) d a$.

\footnotetext{
${ }^{15}$ In a symmetric equilibrium when one firm stocks out (demand exceeds capacity), all the firms stock out, so ex post there is no reason for a consumer to search. However, the equilibrium would be different if search costs were finite. In particular, when search costs are zero, equilibrium prices exhibit price dispersion (see Prescott, 1976, Eden, 1990, and Dana, 1994). In such models firms do not compete in availability since consumers can move freely between firms. In equilibrium firms specialize by offering different prices and availability rates.
} 
Firms

I assume that $n$ firms compete by choosing both price, $p_{i}$, and capacity, $k_{i}$. The firms' costs are $c k_{i}$ which are incurred regardless of sales. The cost $c$ represents the part of the firm's costs that are unrecoverable. The portion of costs which are recoverable (the salvage value) is normalized to zero. Prices are chosen simultaneously and are observable, but I assume that capacity or inventory choices are unobservable both to consumers and to other firms.

Below I consider two models with distinct timings. In the first case inventory (or capacity) is chosen after price, and in the second case inventory (or capacity) is chosen before (or at the same time as) price. The latter model is an adaptation of Deneckere and Peck's (1995) study of simultaneous price and capacity choice with observable capacity.

\section{Consumer Equilibrium}

Consumers choice of which firm to visit depends on prices and their expectation of the service rates, which in turn depend on their expectations of $k_{i}$ and of other consumers' equilibrium strategies.

When $g(a)$ is the probability distribution of $a$ then the probability that an individual consumer obtains the good after visiting firm $i$ is clearly

$$
\int_{\underline{a}}^{\bar{a}} \frac{\min \left(k_{i}, \phi_{i} a\right)}{\phi_{i} a} g(a) d a,
$$

where $\phi_{i} a$ is the demand that firm $i$ faces in equilibrium. Following Deneckere and Peck (1995), a random customer who wants the good conditions his belief about the distribution of $a$ on his own realized demand ${ }^{16}$. The conditional distribution of $a$ given that a random customer wants the good is $g(a)=a f(a) / \mu$. So firm $i$ 's service rate, given its capacity and market share, is

\footnotetext{
${ }^{16}$ This effect can be quite significant. If demand is equally likely to be 10 or 90 , a consumer assigns a probability of .9 to it being the high demand state conditional on wanting the good as compared to the unconditional probability of .5 .
} 


$$
s\left(k_{i} / \phi_{i}\right)=\frac{\int_{\underline{a}}^{\bar{a}} \min \left(k_{i}, \phi_{i} a\right) f(a) d a}{\phi_{i} \mu} .
$$

Note that this probability depends only on the ratio of the firm's capacity to its market share and it is equal to the firm's expected sales $\int_{\underline{a}}^{\bar{a}} \min \left(k_{i}, \phi_{i} a\right) f(a) d a$ divided by its expected demand $\phi_{i} \mu$. As in Deneckere and Peck (1995), the individual consumer's probability of service is the same as the firm's aggregate service rate defined as the expected fraction of realized demand that it serves. ${ }^{17}$

So when inventory is observable the consumer's choice problem is simply to choose the firm that maximizes $\left(v-p_{i}\right) s\left(k_{i} / \phi_{i}\right)$.

Letting $K_{i}=k_{i} / \phi_{i}$ simplifies the notation. In this way the firm's capacity is expressed as if it served the entire market (the capacity the industry offers if every firm acts like firm $i$ ). For $K_{i} \in[\underline{a}, \bar{a}]$, the service rate can be written as

$$
s\left(K_{i}\right)=\frac{\int_{a}^{\vec{a}} \min \left(K_{i}, a\right) f(a) d a}{\mu}=1-\frac{1}{\mu} \int_{K_{i}}^{\vec{a}}\left(a-K_{i}\right) f(a) d a
$$

For $K_{i}>\bar{a}$, the service rate is $s\left(K_{i}\right)=1$, and for $K_{i}<\underline{a}$, the service rate is $s\left(K_{i}\right)=K_{i} / \mu$. The derivative of $s$ is $s^{\prime}\left(K_{i}\right)=\left(1-F\left(K_{i}\right)\right) / \mu$.

Now consider the problem when inventory is unobservable. Let $\kappa\left(p_{i}, p_{-i}\right)$ denote the consumers' expectations of firm $i$ 's capacity given the vector of announced prices and assume that it is uniquely defined. It is straightforward (see Deneckere and Peck, 1995) to show that the market shares, $\left\{\phi_{1}, \ldots, \phi_{n}\right\}$, that equate consumer surplus, $\left(v-p_{i}\right) s\left(\kappa\left(p_{i}, p_{-i}\right) / \phi_{i}\right)$, across all firms are uniquely defined.

LEMMA: (Deneckere and Peck, 1995, Propositions 4, 5, and 6) A consumer equilibrium, $\left\{\phi_{1}, \ldots, \phi_{n}\right\}$, exists given all prices and expected capacities, and is unique whenever prices and expected capacities are restricted to be in the set of undominated firm strategies.

\footnotetext{
${ }^{17}$ Note that the equivalence between the aggregate fill rate and the consumers' individual expected service rate is a property of the assumption of homogeneous consumers.
} 
This lemma describes consumer strategies as a function of prices and expected inventories. The next two sections characterize firms' best response functions for the two different timings. The equilibria of the two static games are the simultaneous solution of the consumer strategies given in the lemma and the firms' best response functions derived below.

\section{Bertrand Timing}

In this section I assume that firms first commit to prices, then observe each other's prices, and finally choose their inventories (or capacities). This assumption is clearly satisfied for firms, such as newspaper stands, magazine vendors, and video rental outlets, which make long-run price decisions and short-run inventory decisions. It also might be appropriate for firms that make short run decisions about the allocation of their capacity across segmented markets (e.g., movie theaters). Price commitments may arise because of advertising, costs of price adjustment, and relationship specific investments.

Because inventory is unobservable the Bertrand game has two, not three stages. Regardless of when the inventory decision is actually made, we can model it as a reducedform game in which consumers decisions and firms' inventory decisions are made at the same time. Since I am interested in the subgame perfect equilibria of the game, I begin by finding the Nash equilibria of this second stage subgame.

Taking prices and consumers' subgame perfect strategies, $\left\{\phi_{1}, \ldots, \phi_{n}\right\}$, as given, firms solve

$$
\max _{k_{i}} p_{i} \int_{\underline{a}}^{\bar{a}} \min \left(k_{i}, \phi_{i} a\right) f(a) d a-c k_{i},
$$

or

$$
\max _{k_{i}} p_{i} \phi_{i} \mu s\left(k_{i} / \phi_{i}\right)-c k_{i} .
$$

The first order condition for the firm is

$$
s^{\prime}\left(k_{i} / \phi_{i}\right) p_{i} \mu=c,
$$


or

$$
\left(1-F\left(k_{i} / \phi_{i}\right)\right) p_{i}=c
$$

which is the standard newsvendor inventory condition for a firm with uncertain demand, $\phi_{i} a$. Inventory is chosen where one minus the stockout rate, $\left(1-F\left(k_{i} / \phi_{i}\right)\right)$, equals the firms markup, $\left(p_{i}-c\right) / p_{i} \cdot{ }^{18}$ So

$$
k\left(p_{i}, \phi_{i}\right)=\left\{\begin{array}{cc}
\phi_{i} F^{-1}\left(\left(p_{i}-c\right) / p_{i}\right) & p_{i} \geq c \\
0 & p_{i}<c
\end{array}\right.
$$

is the profit maximizing inventory strategy for firm $i$ given $p_{i}$ and $\left\{\phi_{1}, \ldots, \phi_{n}\right\}$. Each firm's strategy depends on $\left\{\phi_{1}, \ldots, \phi_{n}\right\}$ but not on other firms' prices. ${ }^{19}$ The other prices only matter in so far as they affect the firms' market shares.

Equation (1) gives the firms' inventory levels as a function of consumers' strategies in any subgame after prices have been announced. So equation (1) not only defines the firms' optimal choice of inventory but also consumers' expectations of firm inventory decisions in any subgame after prices are chosen. So the equilibrium of any subgame is obtained by solving the consumers' maximization problem subject to $\kappa\left(p_{i}, p_{-i}\right)=k\left(p_{i}, \phi_{i}(\vec{p})\right)$, where $\phi_{i}(\vec{p})$ denotes consumers' equilibrium strategies as a function of all $n$ firms' prices.

Thus firms' capacity choices and the consumers mixed strategies are jointly determined by (1) and by the individual consumer's choice problem

$$
\max _{i}\left(v-p_{i}\right) s\left(\kappa\left(p_{i}, p_{-i}\right) / \phi_{i}\right)
$$

which, given (1), can be written

$$
\max _{i}\left(v-p_{i}\right) s\left(F^{-1}\left(\left(p_{i}-c\right) / p_{i}\right)\right)
$$

\footnotetext{
${ }^{18}$ One minus the stockout rate, $\left(1-F\left(k_{i} / \phi_{i}\right)\right)$, is also known in the inventory literature as the firm's type 1 service level. The service rate is also known as the type 2 service level.

${ }^{19}$ Note that for prices less than $c$, the firm will choose $k_{i}=0$ (since $k_{i} \geq 0$ is an omitted constraint).
} 
which is independent of consumers' strategies. Hence competition drives price down to the price that maximize consumer surplus.

Define $p^{*}=\arg \max _{p \geq c}(v-p) s\left(F^{-1}((p-c) / p)\right)$; this is the price that maximizes consumer surplus. I assume concavity so that the price $p^{*}$ is unique. Any firm offering a price $p^{*}$ in the first stage of the game will serve an equal share of the market, and any firm offering a higher or lower price will be have zero share.

Proposition 1. In any equilibrium of the Bertrand timing game all active firms set a price $p^{*}$. When $p^{*}>c$ there is a unique subgame perfect equilibrium in which every firm is active, each firm chooses $(1 / n) F^{-1}\left(\left(p^{*}-c\right) / p^{*}\right)$ units of inventory or capacity, consumers mix over firms with probabilities $\phi_{i}=1 / n$, and firms' earn strictly positive profits. When $p^{*}=c$ then consumers mix over an indeterminate set of active firms.

Note that the equilibrium strategies are determined uniquely because of the assumption that all firms are treated symmetrically. Without that assumption the equilibrium price would still be $p^{*}$, however firms' market shares would be determined by equilibrium expectations.

The Bertrand price announcements convey information about capacity choices and service rates because they alter the firms' incentives to provide additional capacity. By raising its price the firm increases its marginal return to holding inventory. The marginal revenue from an additional unit of inventory is $\left(1-F\left(k_{i} / \phi_{i}\right)\right) p_{i}$. So price increases are associated with a service rate increases. However if a firm raises its price above $p^{*}$ the additional availability it generates (both $k_{i}\left(p, \phi_{i}\right)$ and $s\left(F^{-1}((p-c) / p)\right)$ are increasing in price) is insufficient to offset the effect of the higher price. Consumers' demand at higher prices is zero, so even though its service rate would be higher, a higher priced firm offers no capacity. 
In the next section I show that $p^{*}$ is also the lower bound for prices when firms compete in capacity. But before considering that alternative timing I will explore the determinants of the price floor, $p^{*}$. There are two important questions. First, when is $p^{*}>c$ and second, when is $p^{*}$ larger than the complete information price? I explore the second question in the section 5

Generally speaking, as long as demand is sufficiently uncertain, the Bertrand price $p^{*}$ is strictly greater than marginal cost $c$. If $p^{*}=c$, then $\left(p^{*}-c\right) / p^{*}=0$, and $F^{-1}\left(\left(p^{*}-c\right) / p^{*}\right)=\underline{a}$, so $\sum_{i} k_{i}=\underline{a}$. That is, firms' inventories are set at the minimum level, the level that guarantees that their entire inventory will be sold. The probability of a stockout is one and the probability that the firm has excess inventories is zero. Firms never regret holding too much inventory or capacity. While this seems unrealistic, it can happen either when demand is almost certain or when valuations are very low.

Proposition 2. If $s(\underline{a}) \mu f(\underline{a})<(v-c) / c$ then $p^{*}>c$, otherwise $p^{*}=c$, the firms' stockout rate is one, and inventories are equal to the demand in state $\underline{a}$.

When $s(\underline{a}) \mu f(\underline{a}) \geq(v-c) / c$ the firm's stock out rate is $100 \%$. There is no incentive for the firm to hold speculative inventory to meet uncertain demand. When the minimum inventory guarantees a sufficiently high service rate, i.e., either $\underline{a}$ is large, or potential consumer surplus is small (i.e., $v-c$ is small), then firms will hold only the inventory that sells with certainty. Note also that $\underline{a}=0$ is a sufficient condition for $p^{*}>c$, 
since $s(0)=0$, so enough uncertainty, in the sense of the support of the distribution, is sufficient for $p^{*}>c$.

\section{Cournot Timing}

A more natural timing for many retail environments is that firms first choose inventory or capacity and then choose price. It is also more complex. In this section I assume that firms commit to their inventory or capacity before observing one another's prices.

I actually discuss two closely related timings in this section: a simultaneous choice game in which firms choose price and inventory (or capacity) simultaneously and then consumers decide where to shop given observed prices, and a sequential choice game in which firms first choose inventory (or capacity), then choose price (without observing each other's inventory), and finally consumers decide where to shop given observed prices. ${ }^{20}$ The two extensive form games have the same strategic forms (while the Bertrand game considered earlier has a different strategic form because in that game firms observe each other's prices before choosing inventory). However there are differences in the set of equilibrium in the two games for some refinements that depend on the extensive form. I will primarily describe the model in the language of the simultaneous move game.

Formally this is a game of complete, but imperfect information, with infinite pure strategy sets (for firms). Firms choose price and capacity simultaneous given their expectations of each other's equilibrium price and capacity choices and of consumers' equilibrium strategies. Consumers then observe prices, form expectations of firms' capacities (and service rates), and choose a firm to visit.

Firms' capacity choices depend largely on consumers' equilibrium conjectures about firms' capacities. In order to reduce the multiplicity of outcomes I place some natural

${ }^{20} \mathrm{~A}$ richer model would allow firms to observe each others' inventories, but that is challenging from a modeling perspective because then a firm's price would convey information to consumers about every firms' inventories, not just its own. 
restrictions on strategies. Let consumers' equilibrium expectations about capacity be represented by $\kappa\left(p_{i}\right)$. I assume that the function $\kappa$ is the same for all firms (that is, a firm's identity does not effect consumers' expectations of its capacity) and that all consumers hold the same expectations. ${ }^{21}$ Let $\Phi(\vec{p}): \mathfrak{R}_{n}^{+}$to $\mathfrak{R}_{n}^{+}$describe the vector of consumers' mixed strategies given the $n$ prices. Call $\Phi(\vec{p})$ symmetric if for any $x$ such that $x=\Phi(y)$, and for any $\hat{y}$ such that $\hat{y}$ can be obtained from $y$ by reordering the elements of $y$, then $\hat{x}=\Phi(\hat{y})$ can be obtained from $x$ by reordering the elements of $x$ in the same way. I assume that consumers' mixed strategies are symmetric, so again firm identity does not influence consumer behavior.

I consider equilibria in pure strategies (for firms). Since firms' best response functions are concave whenever other firms are playing pure strategies, the restriction to pure strategy best responses is without loss of generality. However I do ignore potential asymmetric and mixed strategy equilibria of the game.

I define a symmetric pure strategy equilibrium of this game to be a set of price and inventory decisions for the firms, $(\vec{p}, \vec{k})$, a function of conjectures, $\kappa\left(p_{i}\right)$, describing consumers' conjectures about a firm's capacity level as a function of its announced price, and a symmetric function $\Phi(\vec{p})$ which describes consumers' symmetric mixed strategies given the $n$ prices, such that (i) firms' strategies are optimal given the strategies and conjectures of consumers and the strategies of other firms, (ii) in any subgame consumers' strategies are optimal given firms' strategies and their conjectures about capacities, and (iii) consumers' conjectures about firms' capacities satisfy $\vec{k}_{i}=\kappa\left(\vec{p}_{i}\right)$. Note that this game has no proper subgames, so this equilibrium concept is stronger than subgame perfect equilibrium. Also note that I restrict consumers to have pure strategy conjectures about firms' inventory choices even when prices are off the equilibrium path. Nevertheless I believe that this definition captures the minimum of what is rational behavior for consumers.

\footnotetext{
${ }^{21}$ In a model where firms observe each other's capacities before setting price every firm's price would convey information (to consumers) about firm i's capacity and the problem of extracting information about capacities would be much harder.
} 
In contrast to Deneckere and Peck (1995) this game has many equilibria. They show that a unique pure strategy equilibrium exists of the observable output Cournot game if $n$ is large (no pure strategy equilibria exists otherwise). The problem that arises in their game is that firms can deviate by cutting price and simultaneously increasing capacity, which enables them to capture the entire market. This can be seen easily by letting the demand uncertainty collapse to a small interval around the mean $\mu$, in which case a firm can lower its price a very small amount and offer enough capacity to serve the entire market, significantly increasing its profit. Indeed a useful way to think of Peters' and Deneckere and Peck's papers is that by adding enough demand uncertainty (and enough firms) they are able to find a pure strategy equilibrium in a game that typically has none.

In a symmetric pure strategy equilibrium (where every other firm announces a common price) the firm $i$ 's profit maximization problem is

$$
\max _{p_{i}, k_{i}} p_{i} \phi_{i} \mu s\left(k_{i} / \phi_{i}\right)-c k_{i}=\max _{p_{i}, k_{i}} p_{i} \int_{\underline{a}}^{\bar{a}} \min \left(k_{i}, \phi_{i} a\right) f(a) d a-c k_{i}
$$

subject to the constraint

$$
\left(v-p_{i}\right) s\left(\kappa\left(p_{i}\right) / \phi_{i}\right)=\left(v-p^{C}\right) s\left(k^{C} / \phi_{j}\right), \forall j \neq i,
$$

for all $j$ not equal $i$, where $p^{C}$ and $k^{C}$ are the other firms' common equilibrium strategies and consumers' strategies depend on the vector of prices. This set of constraints can be simplified by aggregating over all the other firms, since in equilibrium the other firms have the same market share and service rate, which yields

$$
\left(v-p_{i}\right) s\left(\kappa\left(p_{i}\right) / \phi_{i}\right)=\left(v-p^{C}\right) s\left((n-1) k^{C} /\left(1-\phi_{i}\right)\right) .
$$

Note that consumers' strategies depend on the firm's announced price both because price directly effects the utility offered by that firm and also because it potentially "signals" information about the firm's service rate.

What happens when firm $i$ lowers its price? As consumers switch from other firms to firm $i$ because of the more attractive terms, the remaining firms become more attractive; they have fewer customers chasing the same capacity. Consumers' strategies change until 
the consumer surplus from visiting each firm is again equalized. Unlike the Bertrand Model, firm $i$ cannot capture the entire market by cutting its price because higher priced firms have already committed to offer capacity $k^{C}$.

Consumers' equilibrium strategies depend on prices, but not capacity. So the firm chooses $k_{i}$ to maximize firm profits in the same way as in the Bertrand model. So

$$
k\left(p_{i}, \phi_{i}\right)=\phi_{i} F^{-1}\left(\left(p_{i}-c\right) / p_{i}\right)
$$

is the optimal capacity as a function of price.

As before this condition not only defines the firm's choice of inventory but also consumers' expectations about $k_{i}$ on the equilibrium path. The only conjectures that are consistent with optimal firm behavior are $\kappa\left(p_{i}\right)=\phi_{i} F^{-1}\left(\left(p_{i}-c\right) / p_{i}\right)$. So in particular it must be the case that in a symmetric equilibrium consumers conjecture that firms' inventories satisfy $k^{C}=(1 / n) F^{-1}\left(\left(p^{C}-c\right) / p^{C}\right)$.

This game has a continuum of symmetric pure strategy equilibria. If consumers conjecture that any firm quoting an off-the-equilibrium-path price has zero capacity, $\kappa\left(p_{i}\right)=0, \forall p_{i} \neq p^{C}$, then any price $p^{C} \in[c, v]$ and associated capacity $k^{C}=(1 / n) F^{-1}\left(\left(p^{C}-c\right) / p^{C}\right)$ is supported as a symmetric pure strategy equilibria.

However clearly it is appropriate to place restrictions on off-the-equilibrium path conjectures about relationship between price and consumers' conjecture about firms' inventories. One natural assumption is that consumers conjecture that the firm has chosen the optimal capacity given the observed price. This is especially natural when price and capacity are chosen simultaneously. Another natural assumption is that consumers conjecture the firm has made an error (trembled) when setting its price and that it has not altered its capacity. Each assumption uniquely defines a symmetric pure strategy equilibrium of the game. However I will argue that the latter is less satisfactory because it fails to satisfy a relatively simple forward induction argument discussed below. 
When consumers conjecture that the firm has chosen its capacity optimally given its price, then consumers' off-the-equilibrium-path conjectures take the same form:

$$
\kappa\left(p_{i}\right)=\left\{\begin{array}{cc}
\phi_{i}\left(p_{i}, p\right) F^{-1}\left(\left(p_{i}-c\right) / p_{i}\right) & p_{i} \geq c \\
0 & p_{i}<c
\end{array}\right.
$$

where $\phi_{i}\left(p_{i}, p\right)$ is the consumer equilibrium when all other firms charge a common price $p$. If consumers' conjectures satisfy (2) then the unique symmetric equilibrium is easily obtained.

Proposition 3. When consumers equilibrium conjectures satisfy (2), there exists a unique symmetric pure strategy equilibrium of the Cournot timing game in which every firm offers a common price that is strictly greater than $p^{*}$ and consumers' strategies satisfy $\phi_{i}=1 / n$. As $n \rightarrow \infty$, the equilibrium price converges to $p^{*}$ where industry profits are strictly positive if $p^{*}>c$ and zero otherwise.

Since $\partial \phi_{i}\left(p^{*}, p\right) / \partial p_{i}=0$ and $\partial^{2} \phi_{i}\left(p^{*}, p\right) / \partial p_{i}{ }^{2}<0$, it is clear that firms set prices strictly above $p^{*}$. Because capacity is chosen simultaneously (or first), every firm has a little bit of market power.

The conjectures described by (2) have an appealing forward induction quality. When consumers see a price that is off the equilibrium path they have to reason backwards about what the firm did when it chose its inventory level. Much like reasoning forward about future play, consumers ask themselves if there is any inventory choice such that if they believed the firm chose that inventory level the firm would be better off and furthermore that the firm would have had the incentive to choose that inventory level in the first place. If these two conditions are satisfied for some off-the-equilibrium-path price then the equilibrium does not satisfy a forward induction reasoning that is captured by the Never a Weak Best Response property. ${ }^{22}$

\footnotetext{
${ }^{22} \mathrm{Backward}$ induction is a reasoning process where players look ahead and reason backwards. In a subgame perfect equilibrium it is used to predict future play both on the equilibrium path and at any proper subgame of the original game, including off-the-equilibrium path subgames. That is different from the backwards
} 
Proposition 4. The symmetric pure strategy equilibrium satisfying (2) and characterized in Proposition 3 is the unique symmetric pure strategy equilibrium satisfying the "Never a Weak Best Response” property.

Proposition 4 stops short of claiming that the equilibrium outcome described in Proposition 3 is strategically stable because I cannot use existence theorems to prove it. This is in part because existence theorems would not prove that a symmetric pure strategy stable equilibrium exists, only that some stable equilibrium exists. Secondly, it is difficult to apply strategic stability to games with infinite pure strategy spaces.

Having derived one reasonable equilibrium, I now explore whether other reasonable equilibria exist. Consumers' conjectures can be formed in different ways by assigning greater likelihood to some deviations then others. Another potential set of conjectures for consumers to hold is that the firm played its equilibrium choice for $k_{i}$ regardless of the observed price. This could be justified by assuming that the firm trembled in price but not quantity (or trembled in each with independent probabilities). However these mistakes are more costly for the firm, given price, then the mistake that a firm makes when its capacity is optimal given the choice of price. So if we think consumer believe that firm's mistakes are more likely when they are less costly (in the spirit of Proper equilibria) then this is unlikely to be an equilibrium. Unfortunately I cannot apply properness directly because this game has infinite strategy sets.

Another possibility is that consumers conjecture that the firm trembled in its choice of capacity and that its price is optimal given that capacity. This case is more difficult to solve and not entirely satisfactory because it only assigns beliefs to prices that are consistent with some choice of capacity.

Consumers observe price deviations and have to attribute them to some cause. A forward induction argument says that if the firm could have benefited from the deviation by 
changing consumers' beliefs and actions in a rational way, then consumers should attribute the deviation to a rational forward-looking move. In the usual case the deviator is trying to change expectations of future play. In this case he or she is trying to change expectations of past, but unobservable play. The intuition is the same. Equilibrium is plausible only if it does not allow such deviations.

\section{Observable versus Unobservable Output}

How does the equilibrium price and output when output is unobservable compare to the equilibrium price and output when output is observable, and in particular to the equilibrium derived Carlton (1979) and Deneckere and Peck (1995)? This is clearly the first step to measuring the welfare loss associated with imperfect information. If output is observable, then the firm's optimal output given price is

$$
\left(1-F\left(k_{i} / \phi_{i}\right)\right) v=c
$$

or

$$
k\left(p_{i}, \phi_{i}\right)=\left\{\begin{array}{cc}
\phi_{i} F^{-1}((v-c) / v) & p_{i} \geq c \\
0 & p_{i}<c
\end{array}\right.
$$

Comparing this to (2) it is immediately apparent that holding price fixed, output and service rates are lower under incomplete information (except in the case of a monopolist).

When output is observable the optimal capacity levels are independent of price, so consumers always prefer firms with lower prices. Capacities are also equal to the welfare maximizing capacity; welfare is

$$
\max _{K} v \int_{\underline{a}}^{\bar{a}} \min (K, a) f(a) d a-c k
$$

where $K$ is the sum of firms' individual capacities, so the socially optimal capacity is

$$
(1-F(K)) v=c
$$

or

$$
K=F^{-1}((v-c) / v)
$$


Prices do not affect welfare because demand is assumed to be inelastic. However the equilibrium price level depends on the timing. Under perfect information and Bertrand timing (when price is chosen first), with two or more firms, price is driven down to the zero profit level. Profits are zero when

$$
p \int_{\underline{a}}^{\bar{a}} \min \left(F^{-1}((v-c) / v), a\right) f(a) d a-c F^{-1}((v-c) / v)=0
$$

or

$$
p \mu s\left(F^{-1}((v-c) / v)\right)-c F^{-1}((v-c) / v)=0 .
$$

So

$$
p=\frac{F^{-1}((v-c) / v)}{\mu s\left(F^{-1}((v-c) / v)\right)} c
$$

and since,

$$
s\left(F^{-1}((v-c) / v)\right)=\frac{\int_{\underline{a}}^{\bar{a}} \min \left(F^{-1}((v-c) / v), a\right) f(a) d a}{\mu},
$$

the perfect information Bertrand price is

$$
p_{P I B}=\frac{F^{-1}((v-c) / v)}{\int_{\underline{a}}^{\bar{a}} \min \left(F^{-1}((v-c) / v), a\right) f(a) d a} c .
$$

The price is equal to cost times the ratio of equilibrium capacity to expected sales. The perfect information Bertrand price is strictly greater than unit marginal cost, though exactly equal to the expected cost of a unit sold. Under perfect information, capacity is strictly greater then expected sales unless there is no demand uncertainty, or equivalently $\underline{a}=\bar{a}$. That is the optimal capacity $F^{-1}((v-c) / v)$ always exceeds $\underline{a}$.

A natural question is which is higher, $p_{P I B}$ or $p^{*}$ ? Either may be higher. In particular, when $s(\underline{a}) \mu f(\underline{a})>(v-c) / c$ then $p^{*}=c$ and clearly $p_{P I B}>p^{*}$. But if there is a lot of demand uncertainty and valuations are high $p^{*}>p_{P I B}$. For example if demand is uniformly distributed on [0,100], cost is 10 , and consumers' valuation is 50 , then the symmetric information price is 16.67 (with an equilibrium service rate of 96\%) and the 
Bertrand imperfect information service equilibrium price is 20 (with an equilibrium service rate of $75 \%)$.

There are two effects here. Asymmetric information lowers the equilibrium service rates which lowers the expected costs of unsold inventory and pushes prices down. However, asymmetric information raises the price that firms charge because higher prices signal greater availability. Firms charge bigger markups on lower costs; prices may be higher or lower, but expected profits are higher. In general the more uncertain is demand and the greater are consumer valuations, the more likely it is that the imperfect information price will be higher.

This result has an analogy in efficiency wage literature. Efficiency wages always exceed the reservation wage of the worker but they still may be higher or lower than symmetric information wages. They can be lower because it may be optimal for the worker to work so much harder when effort is contractible that even though he or she is paid their reservation wage their reservation wage for working very hard may be greater than the asymmetric information efficiency wage.

The above comparison is for the Bertrand timing game. Under Cournot timing the comparison will depend on whether price and quantity are chosen sequentially or simultaneously. If firms can simultaneously deviate in both price and quantity, as assumed by Deneckere and Peck (1995), then for small $n$ no pure strategy equilibria exists. For sufficiently large $n$ the Bertrand timing equilibrium price becomes a lower bound for the price in the Cournot timing model; as the number of firms goes to infinity, the equilibrium price approaches this lower bound. However if firms choose output first and then price, and output is observable to other firms when they set price, then firms' prices can be functions of other firms' inventories or capacities. An analysis of this case has not been done and is beyond the scope of this paper. 


\section{Reputations}

Previous work on competition in price and availability has assumed that availability is observable and has not considered reputations for availability. Yet retailers clearly use reputations for availability to influence consumers' shopping decisions. Reputations for availability function very much like reputations for product quality when quality is unobservable. It is not surprising therefore that reputations for greater availability allow firms to charge higher prices and earn potentially higher equilibrium profits.

In this section I consider simple repeated versions of the one period models presented earlier. I make the simplifying assumption that it is either to expensive or impossible to hold inventory from one period to the next, so inventory is chosen separately for each period. While valid for some markets, especially services such as seats in a movie theater or videocassette rentals, this assumption is clearly inaccurate for others. However the advantage of this assumption is that the only aspect of the repeated game that is different from the static game is that consumers' expectations of firms' behavior may change.

For simplicity, I also ignore I restrict attention to reputations for providing the socially optimal service rate. This service rate, $s\left(F^{-1}((v-c) / v)\right)$, is the service rate that the firm would offer if its inventory were observable. Note that this service rate is independent of the price, so a firm with a reputation for providing a service rate of $s\left(F^{-1}((v-c) / v)\right)$ does so regardless of its price, as long as it is incentive compatible for it to do so. I restrict consumers' beliefs: either they believe that the firm chooses inventory $\phi_{i} F^{-1}((v-c) / v)$ and has a service rate of $s\left(F^{-1}((v-c) / v)\right)$, or they believe that the firm chooses inventory $\phi_{i} F^{-1}\left(\left(p_{i}-c\right) / p_{i}\right)$ and has a service rate of $s\left(F^{-1}\left(\left(p_{i}-c\right) / p_{i}\right)\right)$.

Finally, I assume consumers learn the actual availability of each firm at the end of each period, after making their consumption decisions. It would be more realistic to assume consumers update their beliefs about availability based on the outcome of their shopping experiences with each firm. However in that case consumers would not only have different beliefs about firms' service rates because of making different choices about where to buy, 
but also, solely due to chance, two consumers who made the same shopping decisions would have different beliefs about the same firm's service rate. Clearly this is a strong assumption. Allen and Faulhaber (1988) (see also Horstmann and MacDonald, 1994) show that in a related game when quality is observed with a little noise, consumers will put a lot of weight on their equilibrium expectations, and little on the evidence, which undermines the incentive to provide high quality.

Firms choose price and inventory in each period. Each period, given prices, consumers form expectations about inventories and decide which firm to visit. If a firm either never had a reputation or did something to lose its reputation then consumers expect it to offer a service rate of $s\left(F^{-1}\left(\left(p_{i}-c\right) / p_{i}\right)\right)$. Also if a high service rate is not incentive compatible, that is if the firm would be better off deviating to its myopic policy (assuming consumers believed that it will not), then consumers expect the firm to offer a service rate of $s\left(F^{-1}\left(\left(p_{i}-c\right) / p_{i}\right)\right)$. So, to maintain its reputation a firm must have always offered a service rate of $s\left(F^{-1}((v-c) / v)\right)$ and always satisfied its incentive compatibility constraint.

\section{Monopoly}

The socially optimal service rate is self-fulfilling for a monopolist because it is the service rate that maximizes the monopolist's profits. So whether or not a monopolist has a reputation for high service it will offer the high service rate in equilibrium. A monopolist sets price at $p=v$ and extracts all the consumers' surplus, however that is because I have assumed consumers are homogeneous with unit demand. If demand were elastic then as in the case of product quality choice, the monopolist would offer the availability demanded by the marginal consumer. Since a monopolist facing elastic demand does not capture the entire surplus generated from trade at the monopoly price it will hold to little inventory. Nevertheless, in contrast to a firm selling a product with unobservable quality, the monopolist has no incentive to establish a reputation for offering higher service rates. ${ }^{23}$

\footnotetext{
${ }^{23}$ If consumers face an outside option then availability will matter to their decision to visit the firm. For instance a cinema with a local monopoly may want to be known for higher service rates because it
} 


\section{Bertrand Competition}

The equilibrium of the repeated Bertrand game depends on how many firms have reputations. Suppose there are $n \geq 2$ firms. Then there are $n+1$ potential equilibria. Clearly there is one equilibrium in which no firms have reputations. This is just the repeated static game equilibrium. There may also be equilibria in which one firm has a reputation. In that case the firm faces competition only from firms without reputations. Finally there may be equilibria in which 2 or more firms have reputations. In this case there is competition between firms with reputations as well as those without reputations. Although multiple equilibria may exist there is at most one equilibrium in which any particular number of firms have reputations. Whether a particular equilibrium exists will depend on the discount factor, the number of competitors, and the number of firms that have reputations. In particular I show that equilibria may exist in which several firms have reputations even though none exists where only one firm has a reputation.

If only one firm has a reputation for offering the socially optimal service rate, $s\left(F^{-1}((v-c) / v)\right)$, then that firm faces potential competition from one or more other firms without reputations. Therefore it must offer consumers at least $\left(v-p^{*}\right) s\left(F^{-1}\left(\left(p^{*}-c\right) / p^{*}\right)\right)$ in order to capture the market away from firms without reputations. The price $p^{*}$ is the most attractive offer other firms can make, so

$$
(v-\tilde{p}) s\left(F^{-1}((v-c) / v)\right)=\left(v-p^{*}\right) s\left(F^{-1}\left(\left(p^{*}-c\right) / p^{*}\right)\right)
$$

defines the largest price, $\tilde{p}$, that the firm can charge consumers. Since

$$
s\left(F^{-1}((v-c) / v)\right)>s\left(F^{-1}\left(\left(p^{*}-c\right) / p^{*}\right)\right)
$$

the promise of high service allows the firm to charge a price strictly greater than $p^{*}$.

However there is another constraint. The price $\tilde{p}$ needs to be high enough to insure that it is incentive compatible for the firm to offer the socially optimal service rate. The firm

effectively competes with television and other social activities and consumers have to forgo these outside options before learning if a seat is available. See Dana (1999) for a discussion of the monopoly-pricing problem with complete information when consumers face an outside option. 
will deviate from that inventory level when the short-term gains of exploiting its reputation exceed the long run gains of keeping it. The incentive constraint for the firm to offer the high service rate at the price $\tilde{p}$ is

$$
\begin{aligned}
\tilde{p} \mu s\left(F^{-1}\left(\frac{\tilde{p}-c}{\tilde{p}}\right)\right)-c F^{-1}\left(\frac{\tilde{p}-c}{\tilde{p}}\right)+\frac{\delta}{1-\delta} \frac{\pi_{I}}{n} \\
\leq\left[\tilde{p} \mu s\left(F^{-1}\left(\frac{v-c}{v}\right)\right)-c F^{-1}\left(\frac{v-c}{v}\right)\right]\left(1+\frac{\delta}{1-\delta}\right)
\end{aligned}
$$

where $n$ is the number of firms that will compete in the market if the firm's reputation is lost and $\pi_{I} / n$ is the firm's profit in the symmetric continuation equilibrium after it deviates.

This constraint will only hold if $\delta$ is large, or equivalently, if consumers learn very quickly that the firm's service rate differs from the socially optimal level. Let $\delta_{1}(n)$ be defined as the lowest value of $\delta$ for which this constraint is satisfied, so

$$
\begin{aligned}
\tilde{p} \mu s\left(F^{-1}\left(\frac{\tilde{p}-c}{\tilde{p}}\right)\right)-c F^{-1}\left(\frac{\tilde{p}-c}{\tilde{p}}\right)+\frac{\delta_{1}(n)}{1-\delta_{1}(n)} \frac{\pi_{I}}{n} \\
=\left[\tilde{p} \mu s\left(F^{-1}\left(\frac{v-c}{v}\right)\right)-c F^{-1}\left(\frac{v-c}{v}\right)\right]\left(1+\frac{\delta_{1}(n)}{1-\delta_{1}(n)}\right)
\end{aligned}
$$

When two or firms have reputations two things change. First, the firms compete with each other, and second if they deviate in their inventory level they will earn zero profits in the continuation game because the remaining firms with reputations will capture the entire market. Since the firms' market shares are the same whether they deviate in capacity or not (deviations do not alter share), the incentive constraint governing a firm's choice of inventory given the equilibrium price $p$ is

$$
\begin{aligned}
p \mu s\left(F^{-1}\left(\frac{p-c}{p}\right)\right)-c F^{-1} & \left(\frac{p-c}{p}\right) \\
\leq & {\left[p \mu s\left(F^{-1}\left(\frac{v-c}{v}\right)\right)-c F^{-1}\left(\frac{v-c}{v}\right)\right]\left(1+\frac{\delta}{1-\delta}\right) . }
\end{aligned}
$$


In any equilibrium in which more than one firm has a reputation this constraint must hold with equality. If not, any firm could offer a lower price and capture the entire market without violating its incentive compatibility constraint.

Let $p(\delta)$ be the price that makes (3) hold with equality. Will $p(\delta)$ be the equilibrium price? Not necessarily. First, there may be firms without reputations who also compete for consumers. In that case $p(\delta)$ will only be the equilibrium price if $p(\delta) \leq \tilde{p}$. Note that this does not depend on $m$, the number of firms with reputations, or $n$, the number of firms, but on the fact that $m<n$. Let $\delta_{2}$ be the lowest value of delta for which this incentive constraint is satisfied and $p(\delta) \leq \tilde{p}$. That is let $\delta_{2}$ be defined by $p(\delta)=\tilde{p}$ or

$$
\begin{aligned}
\tilde{p} \mu s\left(F^{-1}\left(\frac{\tilde{p}-c}{\tilde{p}}\right)\right) & -c F^{-1}\left(\frac{\tilde{p}-c}{\tilde{p}}\right) \\
= & {\left[\tilde{p} \mu s\left(F^{-1}\left(\frac{v-c}{v}\right)\right)-c F^{-1}\left(\frac{v-c}{v}\right)\right]\left(1+\frac{\delta_{2}}{1-\delta_{2}}\right) . }
\end{aligned}
$$

Note that $\delta_{2}$ does not depend on $n$ and that it is smaller than $\delta_{1}(n)$.

Second, even if $m=n$, it may be in a firm's interest to simultaneously deviate in price and inventory. When $p(\delta)>\tilde{p}$, an equilibrium with reputations may still exist provided $m=n$. Without the threat from other firms, reputable firms will compete price down to $p(\delta)$. Any lower price offer will be understood by consumers to be associated with a deviation to low service. But if $p(\delta)$ is sufficiently high (sufficiently greater than $\tilde{p}$ ), such a deviation (a price reduction combined with a service reduction) may be profitable. The deviator earns a lower profit per consumer, but increases its market share from $1 / n$ to 1 .

To find this incentive constraint, first consider the optimal price deviation. This is the highest price offer that still offers the consumer the surplus he gets from other firms. That surplus is

$$
(v-p(\delta)) s\left(F^{-1}\left(\frac{v-c}{v}\right)\right),
$$

so given an equilibrium price $p$ the optimal deviating price $\hat{p}(p)$ satisfies 


$$
(v-\hat{p}) s\left(F^{-1}\left(\frac{\hat{p}-c}{\hat{p}}\right)\right)=(v-p) s\left(F^{-1}\left(\frac{v-c}{v}\right)\right) .
$$

So the incentive constraint is

$$
\begin{aligned}
\frac{1}{n}\left[p(\delta) \mu s\left(F^{-1}\left(\frac{v-c}{v}\right)\right)\right. & \left.-c F^{-1}\left(\frac{v-c}{v}\right)\right]\left(1+\frac{\delta}{1-\delta}\right) \\
& \geq \hat{p} \mu s\left(F^{-1}\left(\frac{\hat{p}-c}{\hat{p}}\right)\right)-c F^{-1}\left(\frac{\hat{p}-c}{\hat{p}}\right),
\end{aligned}
$$

where $\hat{p}$ depends on $p(\delta)$. Let $\delta_{3}(n)$ denote the lowest value of delta such that no firm wants to simultaneously deviate to a price below $p(\delta)$ and cease to offer the efficient capacity. So $\delta_{3}(n)$ is defined by

$$
\begin{array}{r}
\frac{1}{n}\left[p\left(\delta_{3}(n)\right) \mu s\left(F^{-1}\left(\frac{v-c}{v}\right)\right)-c F^{-1}\left(\frac{v-c}{v}\right)\right]\left(1+\frac{\delta_{3}(n)}{1-\delta_{3}(n)}\right) \\
=\max _{p}\left\{p \mu s\left(F^{-1}\left(\frac{p-c}{p}\right)\right)-c F^{-1}\left(\frac{p-c}{p}\right)\right\} .
\end{array}
$$

Note that $\delta_{3}(n)$ is clearly less than $\delta_{2}$ since $\hat{p}\left(p\left(\delta_{2}\right)\right)=p^{*}$. So $\delta_{3}(n)$ defines the lowest value of delta for which a reputation equilibrium of any kind exists.

Define a reputation equilibrium to be an equilibrium in which one or more firms hold reputations for providing the high service rate. The above results are summarized formally in Proposition 5.

Proposition 5: Consider an infinitely repeated game with Bertrand timing and $n \geq 2$ firms. Let $m$ denote the number of firms with reputations. For $\delta \in\left[0, \delta_{3}(n)\right)$ no reputation equilibria exist. For $\delta \in\left[\delta_{3}(n), \delta_{2}\right)$ a unique reputation equilibrium exists if $m=n$, that is if all $n$ firms have reputations. For $\delta \in\left[\delta_{2}, \delta_{1}(n)\right)$ a unique reputation equilibrium exists for each $m \in\{2, \ldots, n\}$. For $\delta \in\left[\delta_{1}(n), 1\right]$ a unique reputation equilibrium exists for each $m \in\{1, \ldots, n\}$.

Proposition 5 is summarized in Figure 1. 
When only one firm has a reputation industry profits are strictly higher because of the reputation. This is clear because the distortion from the first best service rate is smaller, and yet consumers are no better off. To see this more formally, define the profit for a firm offering price $p$ and normalized capacity $K_{i}=k_{i} / \phi_{i}$ to be $\phi_{i} \pi\left(p, K_{i}\right)$ where

$$
\pi\left(p, K_{i}\right)=p \mu s\left(K_{i}\right)-c K_{i}
$$

As I showed earlier, at price $p^{*}$ and capacity $F^{-1}\left(\left(p^{*}-c\right) / p^{*}\right)$ this profit is nonnegative, and strictly positive when $p^{*}>c$. Now consider the derivative of this function with respect to $K_{i}$ holding consumer surplus fixed, that is

$$
\left(v-p_{i}\right) s\left(K_{i}\right)=U\left(p^{*}\right) .
$$

So substituting the constraint into the profit function,

$$
z\left(K_{i}\right)=\pi\left(\left(v-\frac{U\left(p^{*}\right)}{s\left(K_{i}\right)}\right), K_{i}\right)=v \mu s\left(K_{i}\right)-\mu U\left(p^{*}\right)-c K_{i},
$$

and the derivative of this function with respect to $K_{i}$ is

$$
z^{\prime}\left(K_{i}\right)=v\left(1-F\left(K_{i}\right)\right)-c
$$

which is strictly positive for $K_{i}<F^{-1}((v-c) / v)$, so $\pi\left(\tilde{p}, F^{-1}((v-c) / v)\right)>0$. Thus the firm exploits its reputation by charging a higher price, offsetting all of the benefits to consumers of its higher service rate. The service rate reputation which maximizes the firm's profits is clearly $s\left(F^{-1}((v-c) / v)\right)$, which is the first best service rate.

However when two or more firms with reputations compete not only can industry profits be lower, but firms with reputations may be collectively worse off with reputations than without. The higher the discount factor the less attractive it is to deviate in availability and the weaker is the incentive constraint. In the limit as the discount factor approaches one, availability becomes observable; the equilibrium price approaches the complete information price and profits approach zero. Thus firms might be worse off in an equilibrium where they have reputations then in one where they multilaterally abandoned them. 
There exists some $\hat{\delta} \in\left(\delta_{2}, 1\right]$ such that $p(\hat{\delta})=p^{*}$. For larger values of $\hat{\delta}$ reputations lower equilibrium prices. For smaller values of $\delta$ reputations, if they exist in equilibrium, raise prices.

Proposition 6: In any reputation equilibrium with $m \geq 2$, as $\delta \rightarrow 1$, the equilibrium price approaches the complete information price

$$
p=\frac{F^{-1}((v-c) / v)}{\mu s\left(F^{-1}((v-c) / v)\right)} c,
$$

and equilibrium profits approach zero.

This result, anticipated by Carlton (1978), follows immediately from (3) and the definition of $p(\delta)$. From (3), since $1+\delta /(1-\delta)$ is approaching infinity, it follows that

$$
p \mu s\left(F^{-1}\left(\frac{v-c}{v}\right)\right)-c F^{-1}\left(\frac{v-c}{v}\right)
$$

is approaching zero. Under perfect information $p>c$ and the stockout rate is never $100 \%$,

\section{The Cournot Game}

Here I present some preliminary results on reputation equilibria of the repeated Cournot game. The case of Cournot competition (when output is chosen before price) is more complicated. An important difference is that when only one firm has a reputation for providing the socially optimal service rate it will not serve the entire market.

For simplicity, suppose there is free entry of firms without reputations. So the static equilibrium price of the game without reputations is the equilibrium price of the Bertrand timing game. Suppose now that a single firm with a reputation faces free entry by price-

taking firms without reputations. Many small firms offer $\left(v-p^{*}\right) s\left(F^{-1}\left(\left(p^{*}-c\right) / p^{*}\right)\right)$ and do not have reputations but one firm, firm $i$, has a reputation for choosing the efficient inventory. That firm maximizes

$$
\max _{p_{i}, k_{i}} p_{i} \int_{\underline{a}}^{\bar{a}} \min \left(k_{i}, \phi_{i} a\right) f(a) d a-c k_{i}
$$


subject to

$$
\left(v-p_{i}\right) s\left(F^{-1}((v-c) / v)\right)=\left(v-p^{*}\right) s\left(k_{-i} /\left(1-\phi_{i}\right)\right),
$$

while in equilibrium the other firms offer total capacity given by

$$
k_{-i}=\left(1-\phi_{i}\right) F^{-1}\left(\left(p^{*}-c\right) / p^{*}\right) .
$$

So in equilibrium,

$$
\left(v-p_{i}\right) s\left(F^{-1}((v-c) / v)\right)=\left(v-p^{*}\right) s\left(F^{-1}\left(\left(p^{*}-c\right) / p^{*}\right)\right) .
$$

The price the reputable firm charges is $\tilde{p}$, the same price derived earlier in the Bertrand case. Of course, as in that case it charges that price only if it is incentive compatible to offer the high service rate at $\tilde{p}$. As before if

$$
\begin{aligned}
\tilde{p} \mu s\left(F^{-1}\left(\frac{\tilde{p}-c}{\tilde{p}}\right)\right)-c F^{-1}\left(\frac{\tilde{p}-c}{\tilde{p}}\right)+\frac{\delta}{1-\delta} \frac{\pi_{I}}{n} \\
\leq\left[\tilde{p} \mu s\left(F^{-1}\left(\frac{v-c}{v}\right)\right)-c F^{-1}\left(\frac{v-c}{v}\right)\right]\left(1+\frac{\delta}{1-\delta}\right)
\end{aligned}
$$

then the price $\tilde{p}$ is the equilibrium price for the firm with a reputation. But if $n$ is very large, then this condition is identical to the one that defines $\delta_{2}$. Another way to say this is that $\lim _{n \rightarrow \infty} \delta_{1}(n)=\delta_{2}$

Although the firm with a reputation does not capture the entire market, like in the Bertrand equilibrium when a single firm has a reputation, the firm extracts all the rents created because of its service rate and consumer surplus is the same as in the repeated one shot equilibrium.

Intuitively, what happens as the number of reputable firms, $m$, increases? Clearly the price must stay the same as long as firms without reputations are in the market, since consumers must be indifferent between the firms. So as long as fringe production is positive in equilibrium, the equilibrium price of reputable firms is $\tilde{p}$. Assuming it is incentive compatible for a single reputable firm to maintain its reputation for high service levels at the price $\tilde{p}$, it will be incentive compatible for $m$ firms to maintain their reputations 
when there is more than one firm, since the return to deviating and producing at the short run maximizing service rate is proportional to the firm's market share.

As $m$ increases, at some point fringe share decreases to zero and the price of reputable firms begins to drop below $p^{*}$. Thereafter it continues to fall with $m$. As $m$ increases further the price approaches the Bertrand equilibrium price derived above. So a version of Proposition 6 holds also for the Cournot model (which is closer to the perfect competition model considered by Carlton, 1979).

\section{Extensions and Conclusion}

I have shown that when consumers care about expected availability but availability is unobservable, then prices can act as signals of availability, even in a single period model. Like some efficiency wage models, where workers' expected pay exceeds their reservation wage, firms here earn efficiency profits that induce them to hold more inventories. And like other repeated game models of efficiency wages and product quality reputations, firms can charge higher prices and may earn higher profits by maintaining a reputation for high availability.

The Cournot model also served as an example of an important class of problems for game theory. In the Cournot game firms take observable actions (price) that signal other previously taken hidden actions (inventory). Consumers must use price, and in particular off-the-equilibrium-path prices, to make inferences about past unobservable inventory choices. I argued that the Never-a-Weak-Best-Response property is the right way to capture the forward-induction-like reasoning that parties use when forming expectations about firms' past inventory levels. The model argues for a larger role for using forwardinduction-like arguments when reasoning about past play. ${ }^{24}$

Daughety and Reinganum (1995) consider a similar problem in a model where general product liability induces firms to use price to signal product safety. Increases in

\footnotetext{
${ }^{24}$ See Kohlberg and Mertens (1986) and van Damme (1989).
} 
unobserved product safety reduces the firm's marginal cost (by reducing the size or number of liability claims against them) so a low price signals a safer product. They consider a twostage model in which the firm invest to increase product safety, then learns the stochastic outcome of their investment, and finally sets price. However consumers in their paper do not change the conjectures about past play given the observed prices; they only update their beliefs about the stochastic realization of the firm's quality. In other words their equilibrium conjectures about the firm's R\&D strategy, and the resulting distribution of product safety, are independent of the price offered. This is partly because in response to on-the-equilibrium-path prices consumers assign zero probability to off-the-equilibriumpath play, and partly because the authors assume that off-the-equilibrium-path prices do not alter consumers' equilibrium conjectures about past play (although it is not clear that relaxing this assumption in plausible ways would alter their results). ${ }^{25}$

Several simplifying assumptions might be relaxed. For example, a dynamic model with finite inventory holding costs would certainly be more realistic in some of examples considered in the introduction. Also, the assumption that there is no idiosyncratic demand uncertainty is unrealistic, but not difficult to relax. A more problematic assumption is that consumers value availability equally. When consumers place different values on availability, either because of heterogeneous valuations or search costs, then in equilibrium firms will position themselves at different price and availability points. And even with homogeneous consumers, if search costs are finite then firms may have an incentive to specialize in high price and availability and serve only customers who are rationed at less expensive stores.

Here I consider only one way that firms could signal availability. Advertising, product selection, and product quality, are other firm decisions that might influence consumers' perceptions of availability. In particular one could also relax the assumption

\footnotetext{
25 Another paper with related qualities is Bagwell (1995). He shows that when a Stackelberg leader's output is observed with noise, the follower will not use his observations to alter his conjecture about the firm's capacity. As a consequence the stackelberg leader has no commitment power and the only pure strategy equilibrium is the Cournot equilibrium. Van Damme and Hurkens (1997) derives a mixed strategy equilibrium in which the leader's commitment power is partially restored.
} 
that the firms sell only one product. When firms sell multiple products then the consumer's decision about which firm to visit depends on the expected availability of all of the firm's products and more importantly on how the demands are related. With two products, firms have an incentive to hold more inventories when they sell complementary products because the cost of stock out is the lost margin on the understocked item as well as the margin on any complementary product that did not stock out. And firms have an incentive to hold fewer inventories when they sell substitute products because the cost of stock out is the lost margin on the understocked item less the expected margin on the sale of a substitute product that did not stock out.

It would also be valuable to study repeated games and reputations in models with imperfect information about both price and availability (such as that of Daughety and Reinganum, 1991). The model presented in this paper depends on the unrealistic assumption that consumers know all prices. Yet in many of in the examples I consider consumers only know prices through experience or advertising. While it may be easier for firms to commit to price than availability, that alone does not justify assuming that prices are observable. 


\section{Appendix}

\section{Proof of Proposition 1:}

First I show that announcing $p^{*}$ is an equilibrium strategy. If a firm offers a price $\hat{p}$ less than $p^{*}$, then consumers will not visit that firm because in equilibrium consumers anticipate that the firm will have zero inventory. To see this suppose instead that consumers thought the firm would choose some strictly positive capacity, $\hat{k}_{i}$. Then in equilibrium consumers would visit that firm with a positive probability chosen to equate the expected surplus from the firm to the expected surplus of the firm offering $p^{*}$. However, given consumers' expectations, the firm's incentives are to choose capacity $k\left(\hat{p}, \phi_{i}\right)$ as given in (1), which is strictly lower than consumers expectations, $\hat{k}_{i}$, since by definition of $p^{*}$,

$$
(v-\hat{p}) s\left(F^{-1}((\hat{p}-c) / \hat{p})\right)<\left(v-p^{*}\right) s\left(F^{-1}\left(\left(p^{*}-c\right) / p^{*}\right)\right)
$$

and in a consumer equilibrium,

$$
(v-\hat{p}) s\left(\hat{k}_{i} / \phi_{i}\right)=\left(v-p^{*}\right) s\left(F^{-1}\left(\left(p^{*}-c\right) / p^{*}\right)\right),
$$

which implies that

$$
F^{-1}((\hat{p}-c) / \hat{p})<\hat{k}_{i} / \phi_{i}<F^{-1}\left(\left(p^{*}-c\right) / p^{*}\right)
$$

since $\hat{p}<p^{*}$ and $s$ is increasing. So

$$
k\left(\hat{p}, \phi_{i}\right)=\phi_{i} F^{-1}((\hat{p}-c) / \hat{p})<\hat{k}_{i},
$$

and consumers will not visit the firm and in the subgame they expect $\hat{k}_{i}=0$.

If a firm offers a price above $p^{*}$, then again, given rational expectations about the firm's capacity, consumers will realize that the firm is offering an expected consumer surplus strictly lower then $\left(v-p^{*}\right) s\left(F^{-1}\left(\left(p^{*}-c\right) / p^{*}\right)\right)$ and will not buy from the firm, so the subgame equilibrium expectations are that the firm will not produce.

Suppose $p^{*}=c$. Now I prove that no equilibria exist with active firms offering any other prices. Then the reasoning is identical to the Bertrand reasoning. If the lowest priced firm offers a price greater than $c$ then any other firm can increase its profits and capture the entire market by undercutting that firm's price, because in any subgame after prices have 
been announced the unique equilibrium is for the lowest priced firms to be the only active firms. So in equilibrium at least one firm offers $p^{*}=c$. Since profits are zero, firms are indifferent between being active and inactive. So firms may be inactive in equilibrium, however at least two firms must be active in equilibrium, otherwise the only active firm could raise its price without loosing any market share. Since $p^{*}=c$, there is no incentive to hold speculative inventory, and the industry capacity is simply $\underline{a}$. With $m$ active firms, the market is split evenly by assumption.

Suppose $p^{*}>c$. I now show that $p^{*}$ is the unique equilibrium price for all firms. Suppose firms offered other prices in equilibrium. Then any firm could deviate to $p^{*}$ and offer $\left(v-p^{*}\right) s\left(F^{-1}\left(\left(p^{*}-c\right) / p^{*}\right)\right)$ in equilibrium surplus to consumers in the subsequent subgame and capture the entire market. And they would always strictly want to do so, because profits are strictly positive when $p^{*}>c$. Let $\phi_{i} \pi\left(k_{i} / \phi_{i}\right)$ be the firm $i$ profits if it offers capacity $k_{i}$ and charges equilibrium price $p^{*}$, where

$$
\pi\left(k_{i} / \phi_{i}\right)=p^{*} \mu s\left(k_{i} / \phi_{i}\right)-c k_{i} / \phi_{i} .
$$

Since firms choose inventory to maximize profit, $\max _{k_{i}} \pi\left(k_{i} / \phi_{i}\right) \geq \pi(\underline{a})$, and $\pi(\underline{a})>0$ since

$$
\pi(\underline{a})=p^{*} \mu s(\underline{a})-c \underline{a}=\left(p^{*}-c\right) \underline{a} .
$$

So $\max _{k_{i}} \pi\left(k_{i} / \phi_{i}\right)>0$. So industry profits at $p^{*}$ are strictly positive, and firm profits are strictly positive for any firm with strictly positive market share.

\section{Proof of Proposition 2:}

Let $U(p)=(v-p) s\left(F^{-1}((p-c) / p)\right)$. So $p^{*}=\arg \max _{p \geq c} U(p)$ and $p^{*}$ either is the solution to $U^{\prime}(p)=0$, or $p^{*}=c$. Since

$$
U^{\prime}(p)=-s\left(F^{-1}((p-c) / p)\right)+(v-p) \frac{c^{2}}{f\left(F^{-1}((p-c) / p)\right) p^{3} \mu},
$$




$$
U^{\prime}(c)=-s(\underline{a})+\frac{(v-c)}{c \mu f(\underline{a})} \leq 0,
$$

then the equilibrium price will satisfy $p^{*}=c$ and firms produce only to meet demand at $\underline{a}$. They hold no speculative inventory. So if $s(\underline{a}) \mu f(\underline{a}) \leq(v-c) / c$ then $p^{*}>c$. Q.E.D.

\section{Proof of Proposition 3:}

Suppose that consumers' beliefs satisfy (2). We can substitute (2) into the firm's profit maximization constraint as follows

$$
\left(v-p_{i}\right) s\left(F^{-1}\left(\left(p_{i}-c\right) / p_{i}\right)\right)=\left(v-p^{C}\right) s\left((n-1) k^{C} /\left(1-\phi_{i}\right)\right),
$$

which uniquely defines consumers' equilibrium strategies $\phi_{i}$ in terms of $p_{i}$, the other firms' common price $p^{C}$, and the other firms' common capacity $k^{C}$. Here after I will suppress the superscript $C$ and denote the symmetric equilibrium price and capacity of each firm by $p$ and $k$. Clearly

$$
k=\frac{1}{n} F^{-1}\left(\frac{p-c}{p}\right),
$$

so the constraint can be rewritten as

$$
\left(v-p_{i}\right) s\left(F^{-1}\left(\left(p_{i}-c\right) / p_{i}\right)\right)=\left(v-p^{C}\right) s\left(((n-1) / n) F^{-1}\left(\left(p^{C}-c\right) / p^{C}\right) /\left(1-\phi_{i}\right)\right) .
$$

which defines consumers' strategies $\phi_{i}\left(p_{i}, p\right)$ as a function of firm i's own price and other firms' common price. The left-hand side of $\left(\mathrm{A}^{\prime}\right)$ is maximized at $p_{i}=p^{*}$ and since $s$ is an increasing function, it is clear that for all $p$ the function $\phi_{i}\left(p_{i}, p\right)$ is also maximized at $p_{i}=p^{*}$. So $\partial \phi_{i}\left(p_{i}, p\right) /\left.\partial p_{i}\right|_{p_{i}=p^{*}}=0$.

Differentiating (A1') with respect to $p_{i}$ yields

$$
\frac{\partial \phi_{i}\left(p_{i}, p\right)}{\partial p_{i}}=\frac{U^{\prime}\left(p_{i}\right) \mu\left(1-\phi_{i}\right)^{2}}{(v-p)\left(1-F\left(\left(\frac{n-1}{n}\right) F^{-1}\left(\frac{p-c}{p}\right) /\left(1-\phi_{i}\right)\right)\right)\left(\frac{n-1}{n}\right) F^{-1}\left(\frac{p-c}{p}\right)},
$$

where $U\left(p_{i}\right)=\left(v-p_{i}\right) s\left(F^{-1}\left(\left(p_{i}-c\right) / p_{i}\right)\right)$ and 


$$
U^{\prime}\left(p_{i}\right)=-s\left(F^{-1}\left(\left(p_{i}-c\right) / p_{i}\right)\right)+\left(v-p_{i}\right) \frac{c}{\mu p_{i}} \frac{c}{f\left(F^{-1}\left(\left(p_{i}-c\right) / p_{i}\right)\right) p_{i}^{2}} .
$$

Since $U^{\prime}\left(p^{*}\right)=0$ by definition and $U^{\prime \prime}\left(p^{*}\right)<0$ by assumption, $\partial \phi_{i}\left(p^{*}, p\right) / \partial p_{i}=0$ and $\partial^{2} \phi_{i}\left(p^{*}, p\right) / \partial p_{i}{ }^{2}<0$. Note that $\partial \phi_{i}\left(p_{i}, p\right) / \partial p_{i}$ is continuously differentiable.

To find the symmetric equilibrium price, I implicitly substituting the constraint, (A1), into the objective function and rewrite it as

$$
\max _{p_{i}, k_{i}} p_{i}\left[\phi_{i} \mu-\int_{k_{i} / \phi_{i}}^{\bar{a}}\left(\phi_{i} a-k_{i}\right) f(a) d a\right]-c k_{i} .
$$

The first order condition with respect to $k_{i}$ is

$$
\frac{\partial \pi}{\partial k_{i}}\left(p_{i}, p, k_{i}\right)=0
$$

or

$$
k_{i}=\phi_{i} F^{-1}\left(\frac{p_{i}-c}{p_{i}}\right)
$$

and the first order condition with respect to price is

$$
\begin{aligned}
\frac{\partial \pi}{\partial p_{i}}\left(p_{i}, p, k_{i}\right)= & {\left[\phi_{i}\left(p_{i}, p\right) \mu-\int_{k_{i} / \phi_{i}}^{\bar{a}}\left(a \phi_{i}\left(p_{i}, p\right)-k_{i}\right) f(a) d a\right] } \\
& p_{i} \frac{d \phi_{i}\left(p_{i}, p\right)}{d p_{i}}\left[\mu-\int_{k_{i} / \phi_{i}}^{\bar{a}} a f(a) d a\right] \\
& =0
\end{aligned}
$$

so $\pi_{p_{i}}\left(p_{i}, p, k_{i}^{*}\left(p_{i}, p\right)\right)=0$ implicitly defines firm $i$ 's best response function $p_{i}(p)$. This best response relationship is increasing. First note that by the implicit function theorem and the envelope theorem

$$
\frac{d p_{i}}{d p}=-\frac{\frac{d}{d p} g\left(p_{i}, p, k_{i}^{*}\left(p_{i}, p\right)\right)}{\frac{d}{d p_{i}} g\left(p_{i}, p, k_{i}^{*}\left(p_{i}, p\right)\right)}=-\frac{\frac{\partial \pi}{\partial p \partial p_{i}}\left(p_{i}, p, k_{i}^{*}\left(p_{i}, p\right)\right)}{\frac{\partial^{2} \pi}{\partial p_{i}^{2}}\left(p_{i}, p, k_{i}^{*}\left(p_{i}, p\right)\right)}
$$

Then note that

$$
\frac{\partial^{2} \pi}{\partial p_{i}^{2}}\left(p_{i}, p, k_{i}^{*}\left(p_{i}, p\right)\right)<0
$$


because $\left[\phi_{i} \mu-\int_{k_{i} / \phi_{i}}^{\bar{a}}\left(\phi_{i}\left(p_{i}, p\right) a-k_{i}\right) f(a) d a\right]$ is decreasing in $p_{i}, d \phi_{i}\left(p_{i}, p\right) / d p_{i}$ is negative and decreasing in $p_{i}$, and $p_{i}\left[\mu-\int_{\underline{k}_{i} / \phi_{i}}^{\bar{a}} a f(a) d a\right]=p_{i} \int_{\underline{a}}^{k_{i} / \phi_{i}} a f(a) d a$ is positive and increasing in $p_{i}$, Finally note that

$$
\frac{\partial \pi}{\partial p \partial p_{i}}\left(p_{i}, p, k_{i}^{*}\left(p_{i}, p\right)\right)>0
$$

because $\left[\phi_{i} \mu-\int_{k_{i} / \phi_{i}}^{\bar{a}}\left(\phi_{i}\left(p_{i}, p\right) a-k_{i}\right) f(a) d a\right]$ and $d \phi_{i}\left(p_{i}, p\right) / d p_{i}$ are both increasing in $p$. So $p_{i}(p)$ is strictly increasing.

This implies that the equilibrium is unique. To prove that it exists, since $p_{i}(p)$ is continuous, it suffices to observe that $p_{i}\left(p^{*}\right)>p^{*}$, which follows immediately from (A3), and that $\lim _{x \rightarrow v} p_{i}(x)<v$, since $\lim _{p \rightarrow v} d \phi_{i}\left(p_{i}, p\right) / d p_{i}=-\infty$ (at a price lower than $v$ the firm captures the entire market), so $p_{i}(p)$ has unique fixed point.

The only remaining part of the proof is convergence. First I solve implicitly for the symmetric equilibrium.

$$
\frac{\partial \phi_{i}(p, p)}{\partial p_{i}}=\frac{U^{\prime}(p) \mu\left(1-\phi_{i}\right)^{2}}{(v-p)(1-F(n k))(n-1) k}
$$

and

$$
k=\frac{1}{n} F^{-1}((p-c) / p)
$$

so

$$
\frac{\partial \phi_{i}(p, p)}{\partial p_{i}}=\frac{U^{\prime}(p) \mu\left(1-\phi_{i}\right)^{2}}{(v-p)\left(\frac{c}{p}\right)(n-1) k} .
$$

So $\frac{\partial \phi_{i}(p, p)}{\partial p_{i}}$ is decreasing in $n$, which implies that $p$ is decreasing in $n$. As $n$ approaches infinity, $\frac{\partial \phi_{i}(p, p)}{\partial p_{i}}$ goes to zero for price greater than $p^{*}$, so price must be converging to $p^{*}$.

\section{Proof of Proposition 4:}

In the strategic-form game each firm chooses a price and quantity and consumers choose a probability distribution over firms for each possible realization of prices. 
The NWBR property requires that an equilibrium still be an equilibrium of the modified game after any firm strategies that are never a weak best response to consumers' (and other firms') strategies are eliminated from the game. Given consumers' equilibrium strategies, it follows that I can prune every strategy for the firm in which its inventory choice does not satisfy (2). This is because a strategy that fails to satisfy (2) could never be a weak best response to consumers' (and other firms') equilibrium strategies. The firm can always increase its profits by offering the same price and changing its inventory level to the level satisfying (2). Consumers' behavior would be unchanged.

Note however that inventory strategies other than those given by (2) are not weakly dominated because there exist consumer beliefs that make almost any inventory level a best response. Equation (2) depends on consumers' equilibrium strategy. Once their strategy is pinned down, then the NWBR property can prune firm strategies that are inconsistent with it.

Given (2), a firm's service rate is uniquely defined by prices, and is independent of consumers' strategies. While a firm's inventory level does depend on consumers' strategies, its service rate does not. In any two equilibria where firms' strategies satisfy (2), if a firm charges the same price, then that firm offers the same service rate.

It is also possible to eliminate, by strict dominance, any firm strategies outside of the set $\left(p_{i}, k_{i}\right) \in[0, v) \times(0, \bar{a}]$, so given that firms choose only strategies satisfying (2), once prices are announced, firms' service rates are uniquely determined in equilibrium of the subgame.

Suppose there exists a symmetric Bayesian equilibrium with different payoffs that does not satisfy (2) off the equilibrium path. Then that equilibrium cannot satisfy NWBR because all the off-the-equilibrium path strategies that do not satisfy (2) are never a weak best response and are eliminated. Consumers' off-the-equilibrium path beliefs about the firm's actions will change and only the equilibrium defined by Proposition 3 will remain. 
However it is still necessary to prove that the symmetric Bayesian equilibrium in Proposition 3 satisfies the NWBR property. This requires that we decide how to apply NWBR to infinitesimal consumers. Since consumers remain indifferent over pure strategies, it seems that NWBR cannot eliminate consumer strategies at all. Alternatively, imagine a representative consumer who maximizes his own utility and imagine every consumer adopts that strategy. Then the consumer equilibrium is a dominant strategy equilibrium. It doesn't matter which approach we take. In either case the set of equilibria of the pruned game will stay the same.

The set of strategies for firms can also be pruned. In particular extremely low and extremely high prices on the interval are strictly dominated. Iterative dominance will shrink the set of prices, but as long as the range of prices includes the equilibrium prices, the equilibrium will remain unchanged, and as long as the equilibrium is unchanged the equilibrium strategies will never be pruned. So the equilibrium does satisfy the NWBR property. 


\section{Bibliography}

Allen, Franklin and Faulhaber, Gerald, (1988), "Optimism Invites Deception," Quarterly Journal of Economics, 103 (2) 397-407.

Baywell, Kyle, (1995), "Commitment and Observability in Games," Games and Economic Behavior, 27(4), Winter, 660-80.

Balcer, Y. (1980), "Partially Controlled Demand and Inventory Control: An additive Model," Naval Research Logistics Quarterly, 27, 273-288.

Balcer, Y. (1983), "Optimal Advertising and Inventory Control of Perishable Goods," Naval Research Logistics Quarterly, 30, 609-625.

Bryant, J., 1980, "Competitive Equilibrium with Price Setting Firms and Stochastic Demand," International Economic Review, 21, 619-626

Carlton, Dennis W., (1978), "Market Behavior with Demand Uncertainty and Price Inflexibility," American Economic Review, September, 68, pp. 571-587.

Carlton, Dennis W., “Contracts, Price Rigidity, and Market Equilibrium,” Journal of Political Economy 87 (1979) 1034-1062.

Conslik, John, and Smallwood, Dennis E., 1979, "Product Quality in Markets Where Consumers are Imperfectly Informed," Quarterly Journal of Economics, Vol. 93, no. 1, pp. 1-23.

Dana Jr., James D., "Equilibrium Price Dispersion Under Demand Uncertainty: The Roles of Costly Capacity and Market Structure," Manuscript. Northwestern University, 1994.

Dana Jr., James D., “The Newsvendor Problem With Endogenous Demand,” Manuscript. Northwestern University, 1999.

Daughety, Andrew F. and Reinganum, Jennifer F., "Endogenous Availability is a Search Equilibrium," RAND Journal of Economics, Vol. 22, No. 2, Summer 1991.

Daughety, Andrew F. and Reinganum, Jennifer F., "Search Equilibrium with Endogenous Recall," RAND Journal of Economics, Vol. 23, No. 2, Summer 1992.

Daughety, Andrew F. and Reinganum, Jennifer F., "Endogenous Availability in Search Equilibrium," RAND Journal of Economics, 22 (2), Summer 1991.

Deneckere, R., Marvel, H., and Peck, J., "Demand Uncertainty, Inventories, and Resale Price Maintenance," Quarterly Journal of Economics, August 1996, 885-914.

Deneckere, R. and J. Peck, "Competition over Price and Service Rate when Demand is Stochastic: A Strategic Analysis," RAND Journal of Economics, 1995, 148-162.

Eden, Benjamin, "Marginal Cost Pricing when Spot Markets are Complete," Journal of Political Economy 98 (1990): 1293-1306. 
Gans, Noah, 1999, “Customer Learning and Loyalty When Quality is Uncertain,” mimeo, Wharton, University of Pennsylvania.

Gans, Noah, 1999, "Customer Loyalty and Supplier Strategies for Quality Competition," mimeo, Wharton, University of Pennsylvania.

Gould, John P., "Inventories and Stochastic Demand: Equilibrium Models of the Firm and Industry," Journal of Business, 1978, vol. 51, no. 1, pp. 1-42.

Horstmann, Ignatius and Glenn MacDonald, (1994) "When is Advertising a Signal of Product Quality," Journal of Economics \& Management Strategy, vol. 3, no. 3, pp. 561-584.

Karjalainen (1992), The Newsboy Game. Working Paper, Wharton School, University of Pennsylvania.

Klein, Benjamin, and Leffler, Keith B. (1981). "The Role of Market Forces in Assuring Contractual Performance.” Journal of Political Economy, 89, 615-41.

Lippman, Steven and McCardle, Kevin, "The Competitive Newsboy," Operations Research, 45 (1) 54-65.

Milgrom, Paul and Roberts, John, (1986), "Price and Advertising Signals of Product Quality”, Journal of Political Economy, 94, 796-821.

Parlar (1988) "Game Theoretic Analysis of the Substitutable Product Inventory Problem with Random Demand." Naval Res. Logist. 35, 397-409.

Porteus, E. L. (1990), "Stochastic Inventory Theory", in Handbooks in OR and MS, Vol. 2, D. P. Heyman and M. J. Sobel, editors, Elsevier Science Publishers, 605-652.

Peters, Michael, "Bertrand Equilibrium with Capacity Constraints and Restricted Mobility," Econometrica, Val. 52, No. 5, September, 1984, pp. 1117-1127.

Prescott, E. C. "Efficiency of the Natural Rate." Journal of Political Economy 83 (1976): $1229-1236$.

Robinson, L. W. (1990), “ Appropriate Inventory Policies When Service Affects Future Demand," Working Paper 88-08, Cornell.

Rogerson, W. (1983), "Reputation and Product Quality,” Bell Journal of Economics, 14, 508-16.

Rogerson, W. (1987), "The Dissipation of Profits by Brand Name Investment and Entry When Price Guarantees Quality," Journal of Political Economy, 94 (4), 797-809.

Schwartz B. L. (1966) “A New Approach to Stockout Penalties,” Management Science, 12, B-538-B-544.

Schwartz, B. L. (1970), “Optimal Inventory Policies in Perturbed Demand Models,” Management Science, 16, B-509-B-518.

Shapiro, C. (1982), “Consumer Information, Product Quality, and Seller Reputation,” Bell Journal of Economics, 13, 20-35. 
Shapiro, C. (1983), "Premiums for High Quality as Returns to Reputations", Quarterly Journal of Economics, 98, 659-80.

Van Damme, Eric, and Sjaak, Hurkens, (1997), "Games with Imperfectly Observable Commitment," Games and Economic Behavior, 21(1-2), Oct.-Nov., pp. 282-308.

Wolinsky, A., (1983), "Prices as Signals of Product Quality," Review of Economic Studies, Vol. L (4), No. 163, pp. 647-658. 


\begin{tabular}{|r|c|c|c|c|}
\cline { 2 - 5 } \multicolumn{1}{c|}{} & $\delta \in\left[0, \delta_{1}(n)\right)$ & $\delta \in\left[\delta_{1}(n), \delta_{2}\right)$ & $\delta \in\left[\delta_{2}, \delta_{3}(n)\right)$ & $\delta \in\left[\delta_{3}(n), 1\right]$ \\
\hline$m=1$ & $p=p^{*}$ & $p=p^{*}$ & $p=p^{*}$ & $p=p^{*}$ \\
\hline$m=1$ & None & None & None & $\begin{array}{c}n=1 \Rightarrow p=v \\
n>1 \Rightarrow p=\tilde{p}\end{array}$ \\
\hline$m \in\{2, \ldots, n-1\}$ & None & None & $p=p(\delta) \leq \tilde{p}$ & $p=p(\delta)<\tilde{p}$ \\
\hline$m=n$ & None & $p=p(\delta)>\tilde{p}$ & $p=p(\delta) \leq \tilde{p}$ & $p=p(\delta)<\tilde{p}$ \\
\hline
\end{tabular}

Figure 1:

Equilibrium Prices in Reputation Equilibria 